\title{
Legal support of interpersonal relations in educational activities in a transitive society
}

\author{
Gennady Pratsko*, Natalia Petrasheva, Lyudmila Romanova and Natalia Ryabko \\ Don State Technical University, 344000 Rostov-on-Don, Russian Federation
}

\begin{abstract}
The basis of interpersonal relationships is communication as a means of information exchange and an important factor in influence on the of personality's development. There is a world perception, norms awareness and society values which are perceived through the prism of interpersonal relations. The young people are characterized by the lack of accumulated life experience; values are influenced from the outside, so that influence is the reason for their unstable behavior in the legal field. In a transitive society, all processes are exacerbated, including growing deviant behavior of adolescents. Qualitative work in the organization of legal support of interpersonal relations in the educational environment can help to keep students from committing negative manifestations in interpersonal communication. This form of activity of the teaching staff could be an integral part of the preventive impact on students.
\end{abstract}

\section{Introduction}

Modern society is characterized by a transitional period of development. It is also characterized by modernization and transformation of the previous historical experience that coexist with objectively changing modern realities. The main reason for such an active process of reforming the existing foundations is the processes of globalization. These processes entail the formation of a new world system and contribute to the formation of a new society type

At the same time, the creation of a new type of society is a certain process. This process is typical for any transitive society seeking for «the growth of interdependence and interpenetration of human relations along with the growth of integration of socio-economic life» $[1]$.

There are some inherent regularities in this process. Their presence indicates a society which is in a state of transitivity. First of all, it is "projectness", which is the awareness of the ultimate goal of the ongoing transformations or at least the vector of the direction of society's aspirations. Secondly, it is the informatization of society when the amount of available information increases: a person acquires unlimited opportunities to obtain any kind of information that is not verified, but is perceived as initially true. Such projectness influences the person and forces him to independent structuring of reality around himself, search of a support in life. Also, the availability of information, which is not always

\footnotetext{
${ }^{*}$ Corresponding author: isakova.pravo@,bk.ru
} 
qualitative and reliable, allows him to operate with the obtained information without taking into account the consequences of such using of information.

The Foundation of interpersonal relationships is formed and institutionally determined in adolescence, subsequently determining the behavior of the person throughout adult life. The basis of interpersonal relationships is communication as a means of information exchange and an important factor in influence on teenager's personality development. There is a world perception, norms awareness and society values which are perceived through the prism of interpersonal relations. Throughout life, a person needs to be accepted by others, he is waiting for a positive assessment and positive attitude. These needs are actualized for the individual especially in adolescence.

The search for the foundation for building their own life values, guidelines of behavior in such conditions of reforms is quite difficult. This search is especially difficult if we are talking about people who, due to age characteristics, have not completed the process of formation yet. The young generation, being on the path of transitional development of the state, is faced with a problem when the old foundations, rules of conduct, priorities are no longer relevant, and new strategies for improvement have not been developed yet. In such a situation, young people often choose the anti-social path, as it seems to be more accessible to them, perfect in terms of the implementation of their plans.

The reason for these processes is the availability of the information field, which is not sufficiently censored by the state. The result is a veiled propaganda of violence and cruelty. Due to physiological age reasons young people are not to critically evaluate the received information, so they isolate from it incompetent skills and habits. These skills and habits are deviant, criminogenic and contribute to the formation of criminal behavior.

It is quite rightly noted that it is much more expedient for society to prevent negative behavior than to work with the consequences of a socially dangerous attack. So the Czech teacher Jan Comenius compared the younger generation with young trees and noted that "young trees are easier to make grow in one way or another than an adult tree; in the same way the young generation can be directed to all good in the first years of its life than later, using only scientific methods" [2]. Young people get a significant part of their lives during studying. Usually this period of life is associated with the formation of behavioral characteristics, the acquisition of value orientations. The teaching staff is responsible for the prevention of negative behavior. Currently, there is a process of mutual complication of interpersonal communications in the world of people and technology, which are accompanied by increasing of negative emotional experiences and attitudes. Negative feelings and attitudes, in turn, create barriers in communication and unconditionally require the use of legal support of interpersonal relationships in adolescence.

\section{Results and discussion}

It is necessary to carry out a set of measures during the study at the University that provide legal support of interpersonal relations in educational activities for the comprehensive and full development of the personality of students. Legal support of interpersonal relations in educational activities is purposeful and systematic activities of special subjects (teachers, psychologists, methodologists). Legal support of interpersonal relations in educational activities of students is necessary for the formation of the legal framework, in order to implement the legal knowledge for the comprehensive and full development of students' personality. It is based on socio-pedagogical and legal mechanisms of interpersonal communication, which identify and eliminate violations of interpersonal communication links in educational activities.

Legal support of interpersonal relations in the educational activities of students is able to stop the conflict or offense in time and find a way out of a difficult situation by 
restraining the rule of law. With this form of support, you can help students to find a solution that will help to change the personal position, thinking, behavior and a specific conflict situation.

The quality of interpersonal communication is a certain quality measure of younger generation's life so that youth is a fundamental period of life in which the core patterns of communication are laid and fixed. Legal support of interpersonal relations in educational activities is aimed at raising interpersonal relations to make them more complete. Among the main tasks of legal support of interpersonal relations in educational activities it is necessary to highlight the following: contributing to the establishment of a friendly atmosphere in the process of communication; increasing of interest, empathy to their peers; creating a favorable psychological and legal climate; increasing cohesion with micro and macro group; development of personal mechanisms of understanding and empathy with others; development of communicative and legal skills of communication with peers; disclosure through regulatory characteristics of positive traits and qualities.

Legal support of interpersonal relations in educational activities includes: advisory assistance of the legal support of the entire spectrum of life of students at the University; personal or remote counseling: right and human rights assistance to students; various forms of programs for legal education not only students but also their loved ones to form a legal culture of communication. It is necessary to constantly accumulate such behavioral experience in interaction with others in the course of educational activities, in order to "digest" theoretical knowledge and become a norm and a pattern of behavior.

\section{Conclusions}

The peculiarity of the legal support of interpersonal relations in educational activities is the formation of students in the development of a conscious attitude to the real aspects of life and the formation of skills that contribute to productive socialization and prevention of already existing stereotypes of non-normative communication. It is important to accurate dosing of information taking into account age and individual characteristics of this category of students. The gradual assimilation and complication of the material allows the student with the existing stereotypes of behavior to obtain the necessary set of legal knowledge that will help to implement their successful social interpersonal adaptation.

Timely organization of legal support of interpersonal relations in educational activities helps to keep students from committing negative manifestations in interpersonal communication.

\section{References}

1. F. Webster, Theories of the information society (Routledge, London, 2006)

2. C. Freeman, The Teachers' Book of Wisdom: A Celebration of the Joys of Teaching (Walnut Grove, Walnut Grove 2010) 